\title{
Qualification of TRACE V5.0 Code against Fast Cooldown Transient in the PKL-III Integral Test Facility
}

\author{
Eugenio Coscarelli, ${ }^{1}$ Alessandro Del Nevo, ${ }^{2}$ and Francesco D'Auria ${ }^{1}$ \\ ${ }^{1}$ University of Pisa San Piero a Grado Nuclear Research Group (GRNSPG), Italy \\ ${ }^{2}$ ENEA "Brasimone" Research Center, 40032 Camugnano, Italy \\ Correspondence should be addressed to Eugenio Coscarelli; eugenio.coscarelli@ing.unipi.it
}

Received 4 March 2013; Accepted 14 June 2013

Academic Editor: Keith E. Holbert

Copyright (c) 2013 Eugenio Coscarelli et al. This is an open access article distributed under the Creative Commons Attribution License, which permits unrestricted use, distribution, and reproduction in any medium, provided the original work is properly cited.

\begin{abstract}
The present paper deals with the analytical study of the PKL experiment G3.1 performed using the TRACE code (version 5.0 patch1). The test G3.1 simulates a fast cooldown transient, namely, a main steam line break. This leads to a strong asymmetry caused by an increase of the heat transfer from the primary to the secondary side that induces a fast cooldown transient on the primary sideaffected loop. The asymmetric overcooling effect requires an assessment of the reactor pressure vessel integrity considering PTS (pressurized thermal shock) and an assessment of potential recriticality following entrainment of colder water into the core area. The aim of this work is the qualification of the heat transfer capabilities of the TRACE code from primary to secondary side in the intact and affected steam generators (SGs) during the rapid depressurization and the boiloff in the affected SG against experimental data.
\end{abstract}

\section{Introduction}

Experimental programmes in scaled-down integral test facilities are conducted for solving open issues for current nuclear power plants, for demonstrating the technical feasibility of innovative designs, and for generating reference databases in order to support codes development and assessment [1]. Experimental data are fundamental for demonstrating the reliability of computer codes in simulating the behaviour of an NPP (nuclear power plant) during a postulated accident scenario: in general, this is a regulatory requirement [2].

The OECD/NEA CSNI PKL-2 project (2008-2012) is aimed at studying selected accident scenario at system level and understanding the thermal-hydraulic phenomena and processes occurring in pressurized water reactor design as well as validating and improving complex thermal-hydraulic system codes used in safety analysis. An experimental program, consisting of eight tests (G series), is carried out in integral test facility. The experimental facility is the AREVA NP GmbH PKL-III, installed in Erlangen (Germany), which represents the scaled-down layout of a 1300-MW PWR NPP (KWU-Siemens, Philippsburg NPP unit 2). The third test, so called test G3.1, which will be discussed in this paper, is a fast cool-down transient, namely, a main steam line break. The design of the experiment involves two phases: the first is based on the $0.1 \mathrm{~A}$ break in main steam line as initiating event and the second one consists of the ECCS injections by means of the HPIS connected with the cold legs number 1 and number 4. Another 0.1A main steam line break test was already performed in PKL facility in 1989: the test B5.1.

The acceptance criteria related to such kind of initiating event in typical PWR are focused on ensuring a margin to $\mathrm{DNB}$, preventing the RCS and secondary side overpressure higher than 1.2 times the design value and maintaining a longterm subcriticality. Considering the evolution of the transient as overcooling scenario, the pressurized thermal shock is also investigated. The following parameters are therefore relevant for the analysis:

(i) coolant temperature in affected loop at RPV inlet;

(ii) coolant temperature distribution at core inlet (not applicable to $\mathrm{PKL}$ );

(iii) RCS pressure (outside the scope of the test);

(iv) SG pressures. 
The objective of this work is the assessment of the TRACE code in predicting overcooling transient with focus on primary to secondary side heat transfer in steam generators (SGs) during a rapid cooldown.

\section{Description of the Facility and Experiment}

2.1. PKL III Test Facility Configuration. The PKL facility [3] is a full-height ITF (integral test facility) that models the entire primary system (four loops) and most of the secondary system (except for turbine and condenser) of a 1300-MW PWR NPP. Detailed information on the PKL III ITF and data comparison with other PWR test facilities (LOBI, SPES, BETHSY, and LSTF) can be found in [4].

The facility includes a Reactor Coolant System (RCS), Steam Generators (SG), the interfacing systems on the primary and secondary sides and the break. The RCS includes as the following.

(i) The upper head plenum (UH), which is cylindrical, full-scale in height and 1:145 in volume.

(ii) The upper plenum (UP), full-scale in height and scaled down in volume.

(iii) The upper head bypass, represented by four lines associated with the respective loops to enable detection of asymmetric flow phenomena in the RCS (e.g., singleloop operation).

(iv) The reactor core model, consisting of 314 electrically heated fuel rods and 26 control rod guide thimbles. The maximum electrical power of the test bundle is $2512 \mathrm{~kW}$. Thermocouples are located in the rod bundle for measuring the rod temperatures.

(v) The reflector gap, located between the rod bundle vessel and the bundle wrapper (the barrel in the real plant). It has a flow resistance designed in order to have $1 \%$ of the total primary side mass flow (with the main coolant pump (MCP) in operation) across the reflector gap.

(vi) The lower plenum, containing the 314 extension tubes connected with the heated rods. The downcomer pipes are welded on the lower plenum bottom in diametrically opposite position. Two plates are located in this zone: the fuel assembly bottom fitting and the flow distribution plate.

(vii) The DC (downcomer) is modeled as an annulus in the upper region and continues as two stand pipes connected to the lower plenum. This configuration, as already mentioned previously, permits symmetrical connection of the $4 \mathrm{CL}$ to the RPV and preserves the frictional pressure losses.

(viii) The (four) hot legs is designed taking into account the relevance of an accurate simulation of the two phase flow phenomena, in particular CCFL, in the hot leg piping as in the reactor.

(ix) The (four) cold legs, connecting the SG to the MCP through the loop seal and the MCP to the DC vessel.
The hydrostatic elevations of the loop seals are $1: 1$ compared with the prototype NPP.

(x) The (four) MCPs, which are vertical single-stage centrifugal pumps.

(xi) The PRZ (pressurizer), full height and connected through the surge line to the hot leg number 2.

(xii) The SG primary side, modeled with vertical U-tube bundle heat exchangers like in the prototype NPP. The scaling factor has been preserved by reducing the number of tubes (28 tubes with seven different lengths).

The SG (secondary side) is constituted by the tube bundle zone, seal welded hollow fillers (below the shortest tubes), the DC (with the upper zone annular containing the FW (feed water) ring, the central zone modeled by two tubes outside of the SG housing, and the lower zone with annular shape), and the uppermost part of the SG that models the steam plenum.

2.2. Description of the Test G3.1. The test G3.1 may be characterized in two phases. During the first phase, as soon as the break opening occurs, the SG-1 pressure starts to decrease causing the evaporation of the coolant and, therefore, the enhancement of the heat exchange between primary and secondary systems. Single-phase critical flow at the break happens in this phase. The SG-1 collapsed level drops quickly below $5 \mathrm{~m}$ and the intact SGs corresponding to the loops 2,3 , and 4 are isolated. The MCPs start coasting down with assigned time trends. Once the MCPs are stopped, the butterfly valves close in order to simulate correctly the pressure drop across the MCPs.

The primary coolant temperature and, as a consequence, the pressure, decrease due to the heat exchange in the loop of the affected SG. Also, the PRZ level smoothly drops because the coolant density increases.

No perfect loop to loop mixing is observed given that the temperature in loop 1 at SG-1 inlet is lower than in the other loops. The PRZ empting is also visible during the first $230 \mathrm{~s}$, since cold water from the PRZ surge line enters in the hot leg of loop 2; then hot water coming from the PRZ vessel is detected at the SG-2 U-tubes entrance.

The minimum coolant temperature in the RCS at SG-1 is reached at about $525 \mathrm{~s}$, whereas it is observed at the core inlet at $780 \mathrm{~s}$, when the affected SG is almost emptied. From this time on, the mass flow rate in loop 1 reaches approximately the value of $1.2 \mathrm{~kg} / \mathrm{s}$, which is higher than in the other loops and remains almost unperturbed up to the end of the phase.

Once the heat sink is lost, the energy of the primary system slowly increases again. At $1030 \mathrm{~s}$ from the start of the transient, the HPIS (high pressure injection system) pumps, connected with loops 1 and 4, are switched on and the phase I of the experiment is terminated.

The second phase is characterized by the activation of high pressure injection systems. The injection of cold water from HPIS causes the filling up of the primary system; thus, the primary pressure and PRZ level increase. Coolant temperature stratification is observed in PRZ vessel as well as in cold legs 1 and 4. 
As soon as primary pressure reaches the set point for PRZ safety valve opening $(4.2 \mathrm{MPa})$, the mass flow of the HPIS rises because the primary pressure drops. The PRZ safety valve is controlled on the basis of the pressure drop in the discharge line. The signal for the valve closure occurs when the primary pressure is about $4.05 \mathrm{MPa}$ but it remains partially open with steam flowing through. The primary pressure continues to descend until the cushion of steam in the PRZ top disappears (1820 s). Then, it rises with a rate of $0.05 \mathrm{MPa} / \mathrm{s}$ up to $4.7 \mathrm{MPa}$. As consequence of this, the HPIS mass flow rate decreases rapidly. When the collapsed water level reaches the top of the $\mathrm{PRZ}$, the water is discharged through the PRZ SV (safety valve), which opens on high primary pressure signal. The valve is then regulated in order to maintain the pressure of the system at about 4.15 MPa. The pressure (measured in the upper head) is controlled with a PI controller. During this phase, the pressure of the primary system, the discharged mass flow, the mass flow injected by the HPIS, and the opening of the valve oscillate. The coolant in the primary system is cooled down very slowly. The mass flow rate in the loops remained unperturbed with the loop 1 having larger mass flow rate than the other loops.

At $4400 \mathrm{~s}$, the experiment ends with the coolant temperature in the primary side equal to $210^{\circ} \mathrm{C}$ and the pressure stabilized at $4.15 \mathrm{MPa}$. Figure 1 shows the trends of the main parameters that characterize the experiment: the upper plenum and pressurizer pressure, the secondary side pressure of the intact and affected steam generators, the temperature at core outlet, the outlet temperatures of the intact, and affected SGs.

\section{PKL Nodalization Development with TRACE Code}

The TRACE model of PKL facility, shown in Figure 2(a), consists of two 3D vessel components in cylindrical geometry that model the rod bundle vessel (RBV) and the RPV downcomer, four separate loops that reproduce the geometry, and the hydraulic configuration of the experimental facility. Each one includes a hot leg (HL) an SG, a pump seal, a butterfly valve, a reactor cooling pump, and a CL. The pump seal is nodalized with two pipe components: the first one models the circuit from the SG outlet until the BV, while the second one reproduces the connection of the loop seal with the RCP.

The $3 \mathrm{D}$ vessel component that nodalizes the reactor core vessel is composed by 45 axial levels, two radial rings, and six azimuthal sectors. The radial discretization takes in account the internal configuration of the rod bundle vessel characterized by two main radial regions: the reactor core and reflector gap that simulate the side mass flow through the reactor (core bypass). The core bypass hydraulic resistance in the $3 \mathrm{D}$ component is introduced using a suitable K-factor so that the mass flow at the bypass during the steady state calculation matches the experimental values that correspond to $1 \%$ of the total primary side mass flow. The six azimuthal sectors, in which is subdivided the cross section of the rod bundle vessel, are defined taking in account the reactor coolant loops arrangement and the downcomer upper head bypass piping disposition (see Figure 2(c)). In particular, the HLs 1 and 2 are connected with the sector S4, while the HLs 3 and 4 are connected with the sector S1. The sectors S2, S3, S5, and S6 have connections to the cold legs, respectively, CL1, CL4, CL3, and CL2.

The fuel rods in the core region are modeled by six powered fuel rod heat structures, arranged in azimuthal direction with the power that corresponds to the respective sector. In the axial direction, the fuel rods are nodalized with 18 volumes; the first two levels and the last one are not powered, because there represent the unheated length of the core region.

The DC vessel model consists of 7 axial levels and 2 radial rings (the inner radius has zero fraction flow area in the radial direction to reproduce the annular DC model), while the azimuthal nodalization is the same as that of the rod bundle vessel. The downcomer is connected to the RBV by 1-dimensional components that direct the flow from the downcomer to the lower plenum and from the downcomer to the upper head. The four parallel bypass lines that represent the upper heat bypass are modeled in TRACE with two equivalent parallel bypass pipes.

The thermal-hydraulic behavior of the pressurizer is simulated through three pipes: the first one, nodalized with one volume, models the bottom of the PRZ; the second one, composed of 20 volumes, analyzes the two-phase behavior of the pressurizer; finally, the last hydraulic component represents the top of the PRZ that connects it to the relief steam line, modeled with a pipe. The surge line that realizes the attachment between the PRZ and the HL 2 is nodalized with 1-dimensional component. The characterization of the PRZ relief valve behavior is obtained by means of a simple trip procedure, shown Figure 2(b), in which we require that the valve opens when the pressure in the UP of the $3 \mathrm{D}$ vessel component exceeds the two pressure set points. These set points represent the two conditions for the opening of the relief valve. In order to realize this control system, three valve components are used, two of which are connected in series, and in turn, connected in parallel with the third.

The primary sides of the steam generators are nodalized with a single pipe to represent the U-tube bundle. The modeling of the SG U-tubes in TRACE preserves the flow area and the length (or the volume) with respect to the PKL-III geometry. The TRACE model of the steam generator secondary side is composed of three pipes: the first one models with 61 volumes the rise zone of the steam generator; the second one, composed of 64 volumes, models both the annular top and bottom parts but also the two pipes of the downcomer; finally, the third one (11 volumes) reproduces the hydraulic behavior of the dome of the SG.

The nodalization of the main steam line, shown in Figure 2(a), is composed of a pipe component, with the characteristic to preserve the distance from the break systems to the affected steam generator (SG-1), and a valve component that models the orifice. 


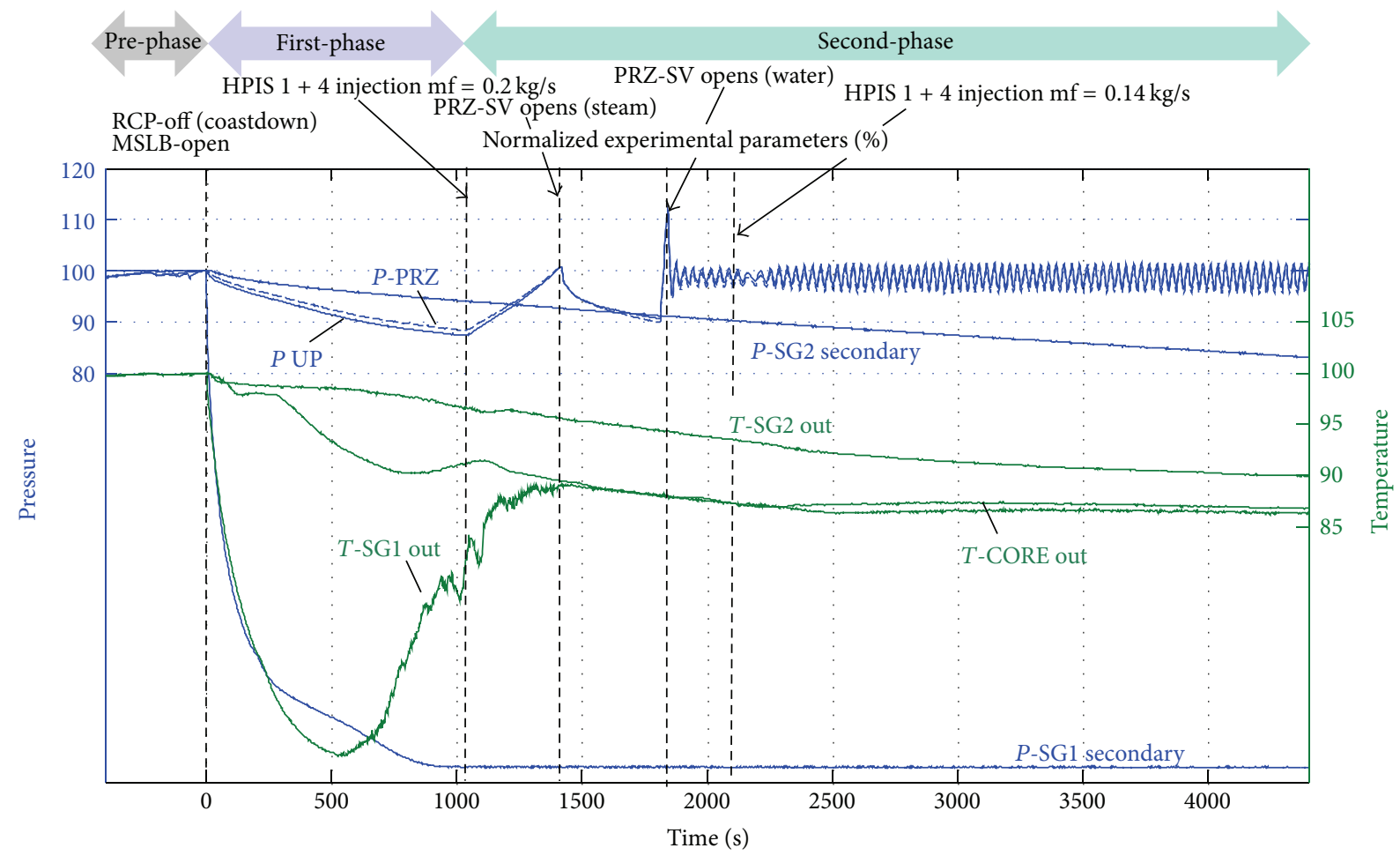

FIGURE 1: Main experimental parameter trends.

\section{Evaluation of the Steady State Results}

The nodalization qualification at steady state level is based on the fulfillment of two steps [5] the following:

(1) the verification and evaluation of the geometrical representation of the model developed;

(2) the capability of the analytical model to achieve stable steady state with the correct initial conditions as in the experiment.

The first item consists of a systematic comparison between the quantities (i.e., volumes, surfaces, lengths and masses), which demonstrate the adequacy of the model in representing the real system.

The second one is the properly defined steady state qualification (see also [6]). This step requires the comparisons between experimental measures (or, as in this case, with the design quantities) and the calculated results at the beginning of the transient (see Table 1).

The selection of the key parameters covers the relevant quantities for evaluating the steady state conditions. Table 1 reports the following quantities: the experimental measures, the codes results including the errors referred to the design data of the test, and the acceptable errors, according to [6].

\section{Qualitative Accuracy Evaluation of the Reference Results}

The comparisons between the experimental data and the calculated results are carried out with the objective of verifying if the code simulations are capable to reproduce the relevant thermal-hydraulic phenomena and processes and to provide a reliable estimation of the parameters relevant for safety analysis. A comprehensive comparison between measured and calculated trends or values is performed, including the following steps: the comparisons between the resulting sequence of main events (see Table 2) and the comparisons between experimental and calculated time trends on the basis of the selected variables (see Figure 3).

Figure 3(a) shows the analytical behaviour of the primary pressure. The simulation is qualitatively well predicted during the first phenomenological phase (occurrence of the main steam line break). In the temporal window that goes from the activation of the HPIS to the opening of the PRZ safety (1030s to $1420 \mathrm{~s}$ ), the pressurization of the primary system simulated by the code is in agreement with the experimental pressure trend. Once the set point of the PRZ safety valve opening is reached (steam released), the decreased pressure part of the calculated upper plenum pressure trend is mainly affected by the different operation of the safety valve with respect to the experiment. In fact, the incorrect setting of the flow area fraction of the PRZ relief valve in the TRACE model causes a greater energy release the effect of which is to reach a minimum of the UP pressure (when the PRZ is completely filled with water) lower than the experimental value. The blowdown of the SG-1 is well predicted by the code simulation. The trend of the pressure in the intact SG (Figure 3(c)) is driven by the setup of the heat losses in the secondary side and the heat exchange between primary and secondary systems of the corresponding loops. 


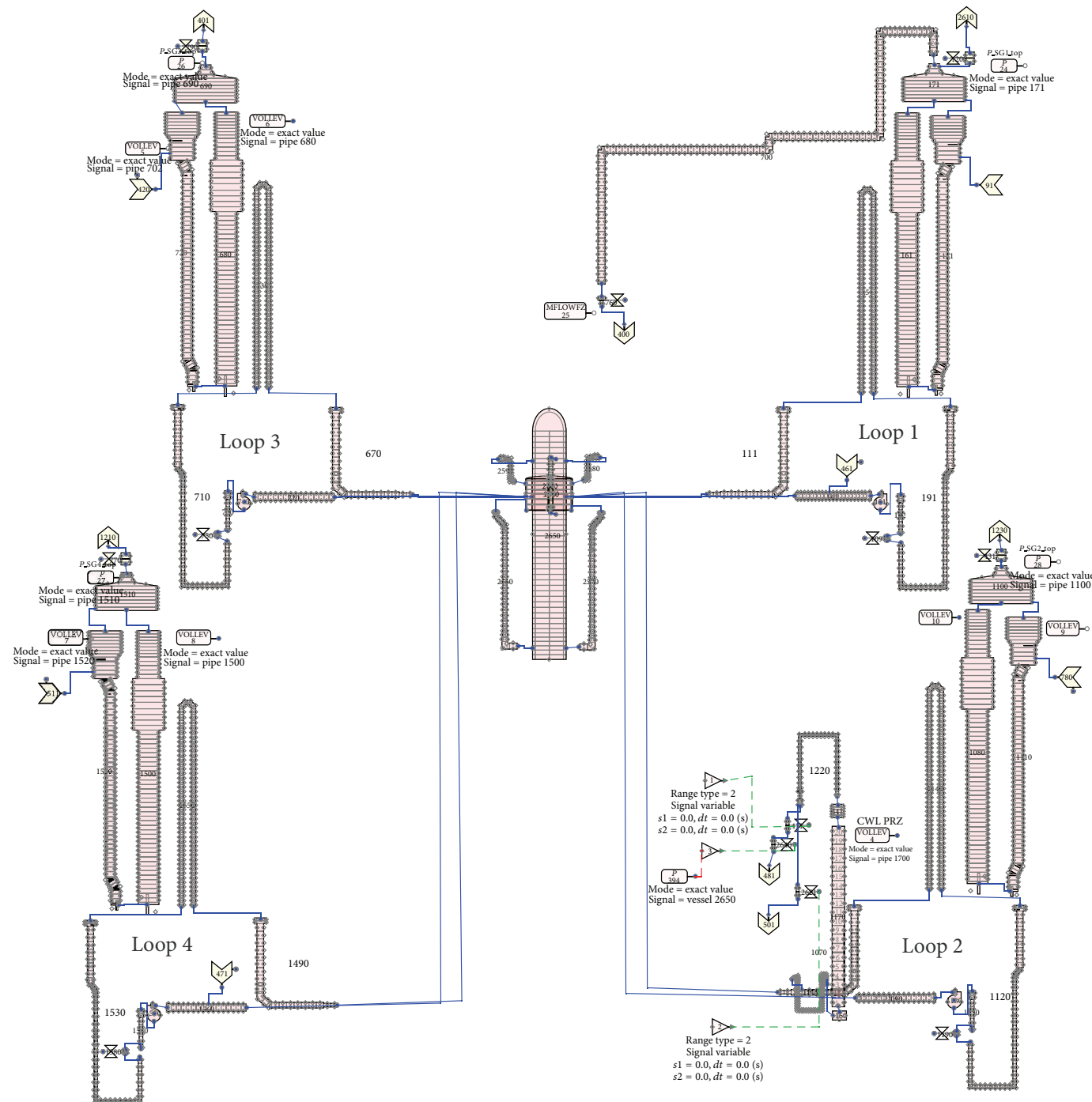

(a)

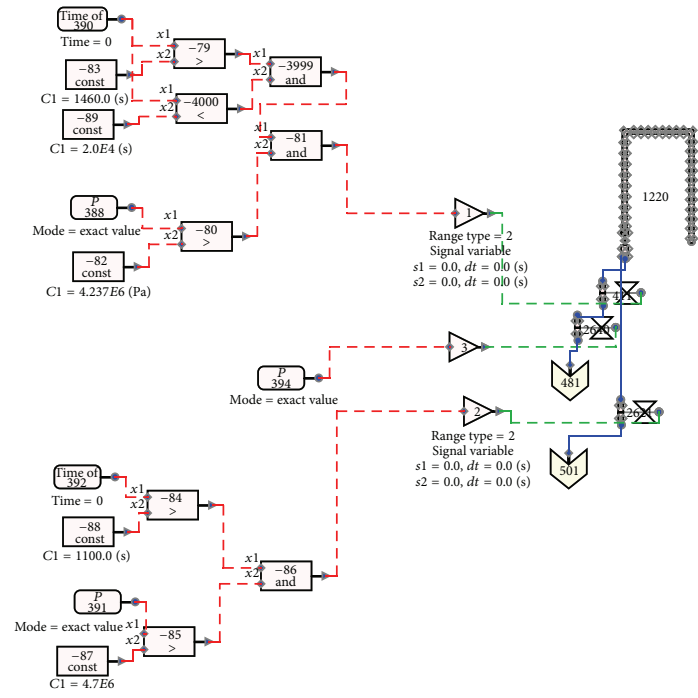

(b)

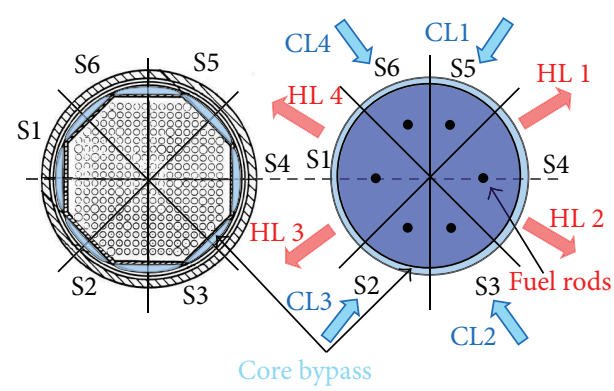

(c)

FIGURE 2: (a) TRACE nodalization of the PKL-2 integral test facility, (b) TRACE model of the relief valve and control systems, and (c) azimuthal and radial nodalizations of the core region. 
TABLE 1: Post test: steady state results.

\begin{tabular}{|c|c|c|c|c|c|c|}
\hline \# & Quantity & Unit & $Y_{\mathrm{DESIGN}}$ & $Y_{\text {EXP }}$ & $\begin{array}{l}\text { TRACE v5 } \\
Y_{\text {calc }}(\mathrm{Er})^{£}\end{array}$ & Acc. $\varepsilon \%$ \\
\hline (1) & Primary circuit power balance & & & & & $2 \%$ \\
\hline$(1.1)$ & Core thermal power & $\mathrm{kW}$ & 260 & $\begin{array}{l}52.39 \\
97.30 \\
110.91\end{array}$ & $259.9(0.0 \%)$ & \\
\hline$(1.2)$ & PRZ heaters thermal power & $\mathrm{kW}$ & 12 & $\begin{array}{l}0.01 \\
1.07 \\
11.89\end{array}$ & - & \\
\hline (2) & Secondary circuit power balance & & & & & $2 \%$ \\
\hline$(2.1)$ & SG-1 power exchanged & $\mathrm{kW}$ & NA & $N A$ & 16.48 & \\
\hline$(2.2)$ & SG-2 power exchanged & $\mathrm{kW}$ & NA & $N A$ & 22.82 & \\
\hline$(2.3)$ & SG-3 power exchanged & $\mathrm{kW}$ & NA & $N A$ & 12.46 & \\
\hline$(2.4)$ & SG-4 power exchanged & $\mathrm{kW}$ & NA & NA & 12.50 & \\
\hline (3) & Absolute pressure & & & & & $0.1 \%$ \\
\hline$(3.1)$ & PRZ (top of the PRZ) & $\mathrm{MPa}$ & 4.2 & 4.15 & $4.11(1.0 \%)$ & \\
\hline$(3.2)$ & Upper plenum pressure & $\mathrm{MPa}$ & 4.2 & 4.21 & $4.21(0.0 \%)$ & \\
\hline (3.3) & SG-1 exit (top of the SG) & $\mathrm{MPa}$ & 3.5 & 3.50 & $3.52(0.6 \%)$ & \\
\hline (3.4) & SG-2 exit (top of the SG) & $\mathrm{MPa}$ & 3.5 & 3.51 & $3.51(0.0 \%)$ & \\
\hline (3.5) & SG-3 exit (top of the SG) & $\mathrm{MPa}$ & 3.5 & 3.51 & $3.50(0.3 \%)$ & \\
\hline$(3.6)$ & SG-4 exit (top of the SG) & $\mathrm{MPa}$ & 3.5 & 3.52 & $3.50(0.6 \%)$ & \\
\hline$(4)$ & Coolant temperature & & & & & $0.5 \%$ \\
\hline$(4.1)$ & Core inlet (lower plenum top) & ${ }^{\circ} \mathrm{C}$ & NA & 244.1 & $243.94(0.1 \%)$ & \\
\hline$(4.2)$ & Core outlet (upper plenum) & ${ }^{\circ} \mathrm{C}$ & 246 & $\begin{array}{l}244.5 \\
243.5 \\
243.3 \\
243.4\end{array}$ & $244.07(0.2 \%)$ & \\
\hline (5) & Rod surface temperature & & & & & $10^{\circ} \mathrm{C}^{\wedge M}$ \\
\hline$(5.1)$ & Max clad temp./Height with ref. to BAF & ${ }^{\circ} \mathrm{C} / \mathrm{m}$ & NA & $\begin{array}{l}241.9 \\
242.7 \\
242.3 \\
242.2\end{array}$ & $244.48 / 5.58\left(1.78^{\circ} \mathrm{C}\right)$ & \\
\hline (6) & Mass inventory in primary circuit & & & & & $2 \%^{\wedge \wedge}$ \\
\hline$(6.1)$ & PMI (with PRZ and without ACCs) & $\mathrm{kg}$ & NA & $N A$ & NA & \\
\hline (7) & Mass inventory in secondary circuit & & & & & $5 \%^{\wedge \wedge}$ \\
\hline (7.1) & SG-1 (vessel) & $\mathrm{kg}$ & NA & $N A$ & 474 & \\
\hline$(7.2)$ & SG-2, 3, 4 (vessel) & $\mathrm{kg}$ & NA & $N A$ & 798 & \\
\hline (8) & Mass flow rates & & & & & $2 \%$ \\
\hline$(8.1)$ & CL 1 mass flow rate & $\mathrm{kg} / \mathrm{s}$ & 34 & 33.7 & $33.41(0.87 \%)$ & \\
\hline$(8.2)$ & CL 2 mass flow rate & $\mathrm{kg} / \mathrm{s}$ & 34 & 33.7 & $33.42(0.84 \%)$ & \\
\hline$(8.3)$ & CL 3 mass flow rate & $\mathrm{kg} / \mathrm{s}$ & 34 & 33.6 & $33.36(0.72 \%)$ & \\
\hline$(8.4)$ & CL 4 mass flow rate & $\mathrm{kg} / \mathrm{s}$ & 34 & 33.5 & $33.44(0.18 \%)$ & \\
\hline$(8.5)$ & SG-1 feed water mass flow rate & $\mathrm{kg} / \mathrm{s}$ & $0.0^{* *}$ & 0.0 & 0.0 & \\
\hline$(8.6)$ & SG-2, 3, 4 feed water mass flow rate & $\mathrm{kg} / \mathrm{s}$ & $0.0^{* *}$ & 0.0 & 0.0 & \\
\hline$(8.7)$ & SG-1 steam line mass flow rate & $\mathrm{kg} / \mathrm{s}$ & $0.0^{* *}$ & 0.0 & 0.0 & \\
\hline$(8.8)$ & SG-2, 3, 4 steam line mass flow rate & $\mathrm{kg} / \mathrm{s}$ & $0.0^{* *}$ & 0.0 & 0.0 & \\
\hline
\end{tabular}

${ }^{E}$ The \% error is defined as the ratio |reference design value-calculated value $\mid$ reference design value. The "dimensional error" is the numerator of the above expression. The error is evaluated against the $Y_{\text {DESIGN }}$ data.

${ }^{\wedge}$ Consistent with other errors.

${ }^{\wedge \wedge}$ Consistent with power error. The errors are calculated in ${ }^{\circ} \mathrm{C}$.

${ }^{* *}$ Steam line and feed water system closed. 
TABLE 2: Post test: resulting sequence of main events.

\begin{tabular}{|c|c|c|c|c|}
\hline \# & Event description & $\operatorname{EXP}(\mathrm{sec})$ & $\begin{array}{c}\text { GRNSPG UNIPI } \\
\text { TRACE5 }\end{array}$ & Note \\
\hline 1 & Start of transient (break opening) in SG number 1 steam line & 0 & 0 & Imposed \\
\hline 2 & Heaters in SG number 1 switched off & 0 & 0 & Imposed \\
\hline 3 & Trip of the MCP and coastdown & 0 & 0 & Imposed \\
\hline 4 & PRZ heaters switched off & 0 & 0 & Imposed \\
\hline 5 & Butterfly valves closure & 210 & 210 & Imposed \\
\hline 6 & MCPs completely stopped & 210 & 210 & Imposed \\
\hline 7 & Affected SG level lower than $<8.0 \mathrm{~m}$ & 6.4 & 9 & \\
\hline 8 & Affected SG level lower than $<5.0 \mathrm{~m}$ & 32 & 175 & \\
\hline 9 & Affected SG level lower than $<2.5 \mathrm{~m}$ & 393 & 422 & \\
\hline 10 & Affected SG level lower than $<1.0 \mathrm{~m}$ & 579 & 612 & \\
\hline 11 & Affected SG level lower than $<0.1 \mathrm{~m}$ (emptied) & 828 & 819 & \\
\hline 12 & Affected SG pressure lower than $<3.0 \mathrm{MPa}$ & 10.4 & 10 & \\
\hline 13 & Affected SG pressure lower than $<2.0 \mathrm{MPa}$ & 47 & 49 & \\
\hline 14 & Affected SG pressure lower than $<1.0 \mathrm{MPa}$ & 164 & 177 & \\
\hline 15 & Affected SG pressure lower than $<0.5 \mathrm{MPa}$ & 435 & 404 & \\
\hline 16 & Minimum PRZ level & 819 & 806 & \\
\hline 17 & Minimum mass flow rate in loop 2 to 4 & 1060 & NA & \\
\hline 18 & Minimum coolant temperature in CL number 1 (phase 1 ) & $525-565$ & 608 & \\
\hline 19 & Minimum core inlet temperature (phase 1 ) & $780-840$ & 867 & \\
\hline 20 & HPIS activated in loops number 1 and number $4(0.2 \mathrm{~kg} / \mathrm{s})$ & 1030 & 1030 & Imposed \\
\hline 21 & Maximum temperature difference across SG number 1 (phase 1) & $380-420$ & 369 & \\
\hline 22 & PRZ safety valve 1st opening (steam released) & 1420 & 1378 & Steam discharged \\
\hline 23 & Water released through the PRZ safety valve & 1840 & 1887 & \\
\hline 24 & End of calculation & 4410 & 4410 & \\
\hline
\end{tabular}

Figures 3(d) and 3(e) compare the trends of the PRZ and the SG-1. The results show a qualitative agreement with the experiment. It may be noted that the simulation did not predict the riser swelling in SG-1 immediately after the break opening. The PRZ level is driven by the primary system cooldown during the first phase and by the ECCS injection during the second phase. The simulation is consistent with the experimental data. Regarding the level in the affected SG, the results show a qualitative agreement with the experiment. It is important to emphasize that the simulation did not predict the riser swelling in SG-1 immediately after the break opening.

From Figure 3(f) to Figure 3(i), the calculated mass flow rates in the loops are compared with the experimental data. From the beginning of the transient up to about $160 \mathrm{~s}$, the mass flow rate is mainly driven by the MCP rotation. The coastdown is provided in the specifications as boundary condition and it is setup correctly. As soon as the MCPs are stopped, the single-phase NC (natural circulation) drives the mass flow in the primary system. It derives from the balance between driving and resistant forces. Driving forces are the result of fluid density differences occurring between descending side of U-tubes and DC vessel (cold side) and core zone and ascending side of U-tubes (hot side). Resistant forces are due to irreversible friction pressure drops along the entire loop. The simulations provide good predictions of the $\mathrm{NC}$ in the affected loop (Figure 3(f)). Finally, the prediction of the NC by the code in the intact loops shows a qualitative agreement with the experimental data.

Figure $3(\mathrm{j})$ reports the mass flow rate through the break. The parameter is calculated by TRACE code in relation to the study of behavior choked flow models, using a series of default multipliers. The reason of this choice is related to the fact the TRACE code offers two different coefficients to adjust the choked flow model [7]: the subcooled multiplier and the two-phase multiplier. These values are gain factors applied to the respective equations depending on the regime at the throat of the break. It is worth mentioning that RELAP5 Ransom-Trapp model allows the analyst to use three different coefficients. The first two are equivalent to those used in TRACE, whereas the third one is applied when the singlephase vapor is found at the throat. Hence, when addressing an MSLB case using TRACE, there is no coefficient to adjust the choked flow under single-phase vapor in contrast to the options given to the RELAP users. The time trend of the break mass flow using this approach shows a good agreement with the experimental data also confirmed by a good prediction of the maximum break mass flow.

Figure $3(\mathrm{k})$ shows that the lower plenum coolant temperature is qualitatively well predicted by the code run. The 
TABLE 3: Post test: summary of results obtained by application of FFT-BM—overall transient.

\begin{tabular}{|c|c|c|c|c|}
\hline \multirow{3}{*}{$\#$} & \multicolumn{2}{|c|}{ Parameter } & \multirow{2}{*}{\multicolumn{2}{|c|}{$\begin{array}{l}\text { TRACEv5 } \\
(0-4410 \mathrm{~s})\end{array}$}} \\
\hline & \multirow{2}{*}{ Description } & \multirow{2}{*}{ ID } & & \\
\hline & & & AA & WF \\
\hline 1 & UP pressure & $P R D B O P$ & 0.317 & 0.035 \\
\hline 2 & PRZ pressure & P DH MB 50 & 0.322 & 0.033 \\
\hline 3 & SG-1 pressure & P DE1 SEK MB 50 & 0.053 & 0.033 \\
\hline 4 & SG-4 pressure & P DE4 SEK & 0.033 & 0.062 \\
\hline 5 & LP coolant (liquid) temp. & TF UP OBEN & 0.147 & 0.056 \\
\hline 6 & UP coolant (liquid) temp. & TF OP ME11/1 & 0.142 & 0.057 \\
\hline 7 & UH coolant (liquid) temp. & TF DK ME 19 & 0.436 & 0.054 \\
\hline 8 & PRZ coolant (liquid) temp. (at $1.716 \mathrm{~m}$ ) & TF DH ME 3 & 0.119 & 0.056 \\
\hline 9 & SG 1 outlet coolant (liquid) temp. & TF KS1 DE-AUS & 0.171 & 0.053 \\
\hline 10 & SG 3 outlet coolant (liquid) temp. & TF KS2 DE-AUS & 0.107 & 0.053 \\
\hline 11 & SG 1 outlet mass flow & F DE1 AUS WR-VR-VLR & 0.033 & 0.066 \\
\hline 12 & SG 2 outlet mass flow & F DE4 AUS WR-VR-VLR & 0.033 & 0.048 \\
\hline 13 & Steam line 1 BRK nozzle & F LBA 10 CF 001 & 0.322 & 0.073 \\
\hline 14 & Integral BRK flow rate & - & 0.036 & 0.032 \\
\hline 15 & DC RPV inlet 1/outlet 1 & DP RDB EIN/AUS-1 & 0.482 & 0.058 \\
\hline 16 & DP inlet-outlet SG 1 (BL) & $D P D E 1 E / A$ & 1.736 & 0.078 \\
\hline 17 & DP inlet-outlet SG 4 (IL) & $D P D E 4 E / A$ & 1.610 & 0.084 \\
\hline 18 & DP across BRK device & DP FD-LECK DE10 & 0.421 & 0.081 \\
\hline 19 & PRZ collapsed level & H JEF 10 CL 001 & 0.096 & 0.078 \\
\hline 20 & SG-1 riser collapsed level & H DE1 SEK STGRM/GES & 0.201 & 0.079 \\
\hline 21 & SG-1 DC collapsed level & H JEA 10 CL 851 & 0.249 & 0.081 \\
\hline 22 & SG-2 riser collapsed level & H DE2 SEK STGRM/GES & 0.104 & 0.049 \\
\hline 23 & Hottest cladding temp. & TW K10/6 & 0.114 & 0.06 \\
\hline Total average accuracy & & Total (23 parameters) & 0.226 & 0.054 \\
\hline
\end{tabular}

quantitative discrepancies among the analytical parameters and the experimental datum are a consequence of the energy imbalance between the core power, heat losses, and the primary to secondary heat exchanges. This is particularly evident in last phase of the transient (between $2500 \mathrm{~s}$ and the EoT (end of transient)), in which the experimental datum is approximately constant, while the calculated value decreases progressively. Figure 3(1) shows the CL coolant temperature at SG-1 outlet. The correct simulation of this parameter trend is one of the objectives of the test. Indeed, it is connected with the depressurization of the affected SG, the heat exchange primary to secondary, and drives the natural circulation in the loop.

\section{Quantitative Accuracy Evaluation by Fast Fourier Transform-Based Method}

Fast Fourier Transform-Based Method (FFTBM) [8], developed at the University of Pisa, is used for the quantification of the accuracy of the code results. This tool gives an accuracy coefficient (AA) and a weighted frequency (WF) (see (1)) for each variable and for the overall transient. Roughly, the value assumed by AA represents the error in the calculation of the considered variable. The WF factor provides information whether the calculated discrepancies, between the measured and calculated trends, are more important at low frequencies (small value of WF) or high frequencies (large value of WF). In this last case, it can be stated that the discrepancies come from various kinds of noise and so it is less important,

$$
\mathrm{AA}=\frac{\sum_{n=0}^{2^{m}}\left|\widetilde{\Delta} F\left(f_{n}\right)\right|}{\sum_{n=0}^{2^{m}}\left|\widetilde{F}_{\exp }\left(f_{n}\right)\right|}, \quad \mathrm{WF}=\frac{\sum_{n=0}^{2^{m}}\left|\widetilde{\Delta} F\left(f_{n}\right)\right| \cdot f_{n}}{\sum_{n=0}^{2^{m}}\left|\widetilde{\Delta} F\left(f_{n}\right)\right|}
$$

In (1), $\widetilde{\Delta} F\left(f_{n}\right)$ and $\widetilde{F}_{\exp }\left(f_{n}\right)$ are the Fourier transform of the error function and experimental signal; $f_{n}$ is the frequency.

Table 3 summarizes the results obtained by the simulation for the overall transient. The table includes the detail of the parameters selected for the application of the FFTBM, the labels that identify the parameters in the experimental database, the values of the accuracies, and of the weighted frequency.

The selected parameters are 23 (see Table 3 ). They are selected as the minimum number relevant to describe the transient, considering both the peculiarities of the transient and the availability of the experimental data. Those parameters are then combined to give an overall picture of the accuracy of a given calculation. The total average amplitude of the transient is the result of the sum of all the average amplitudes with their "weights." The "weight" of 


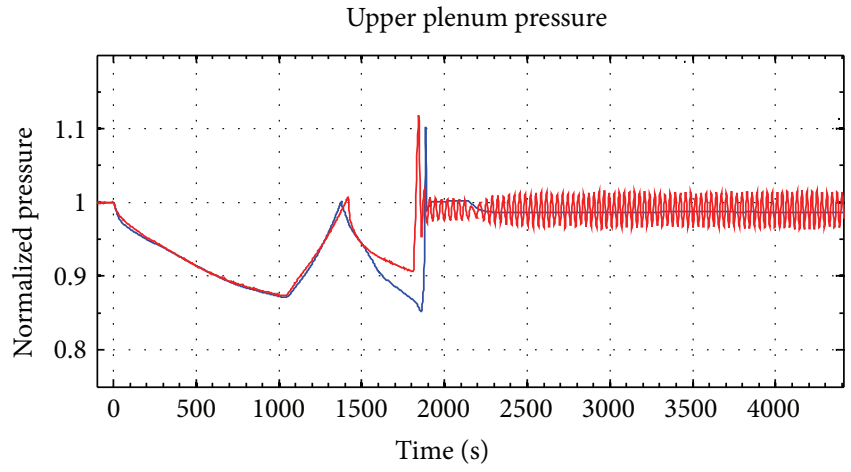

(a)

SG-2 pressure secondary (top of SG)

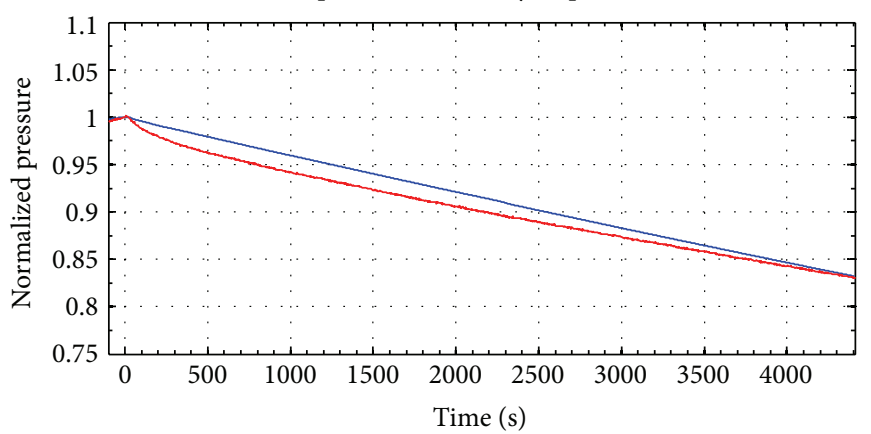

(c)

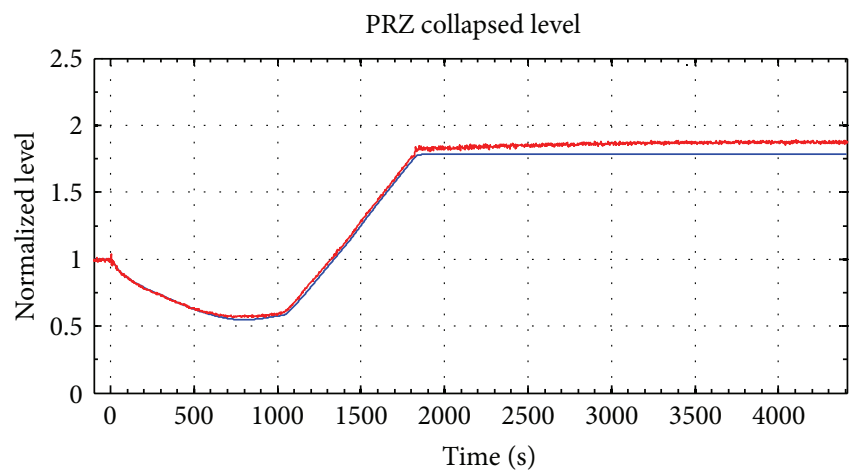

(e)

Mass flow loop 2

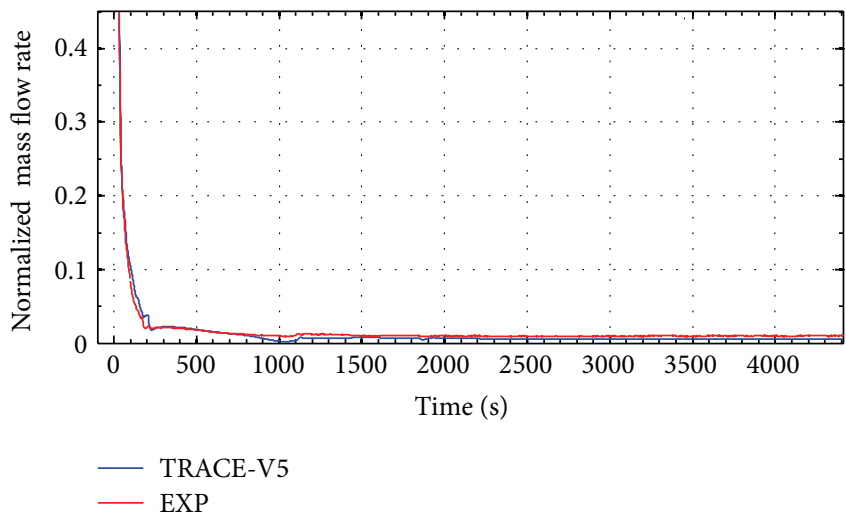

(g)

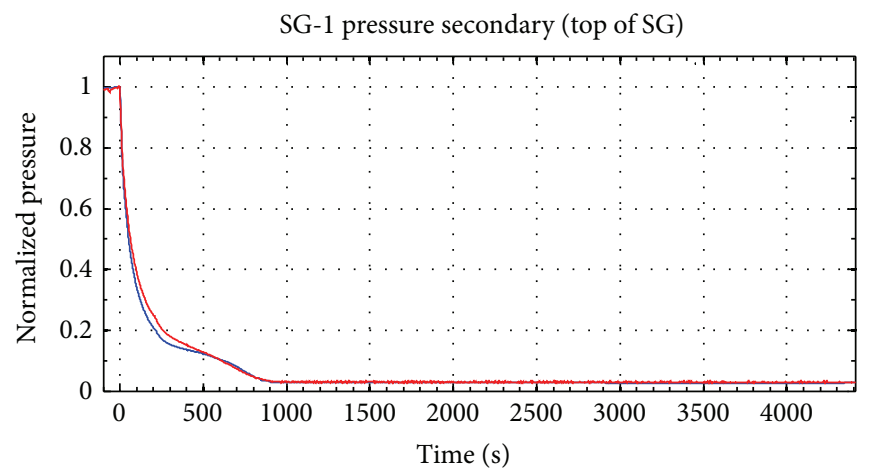

(b)

SG-1 collapsed level

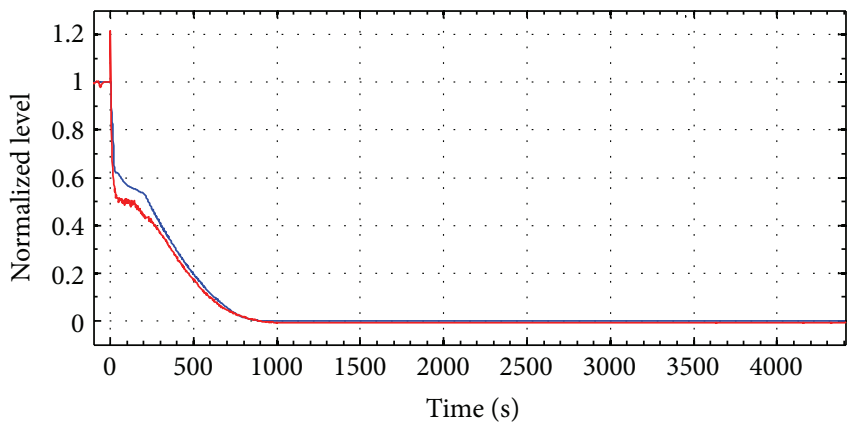

(d)

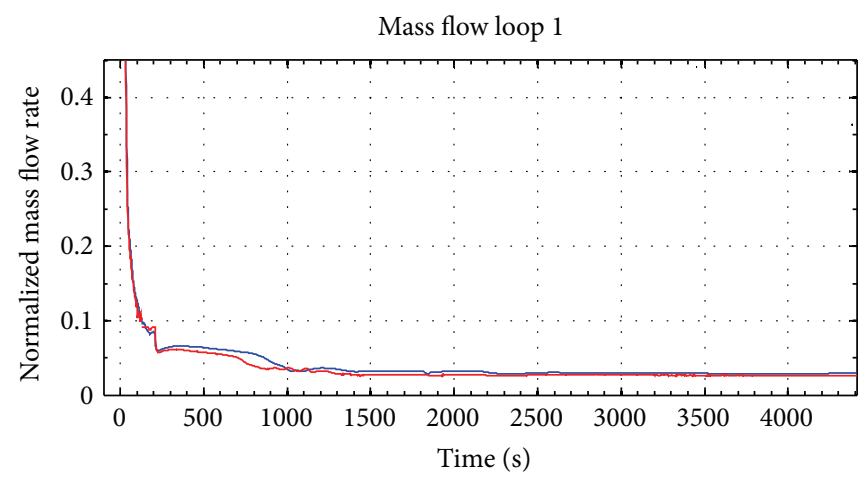

(f)

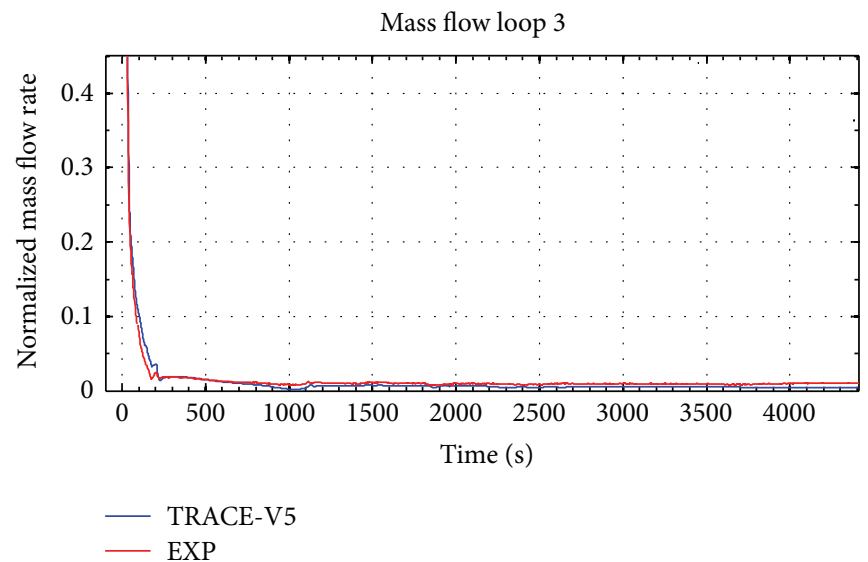

(h)

Figure 3: Continued. 


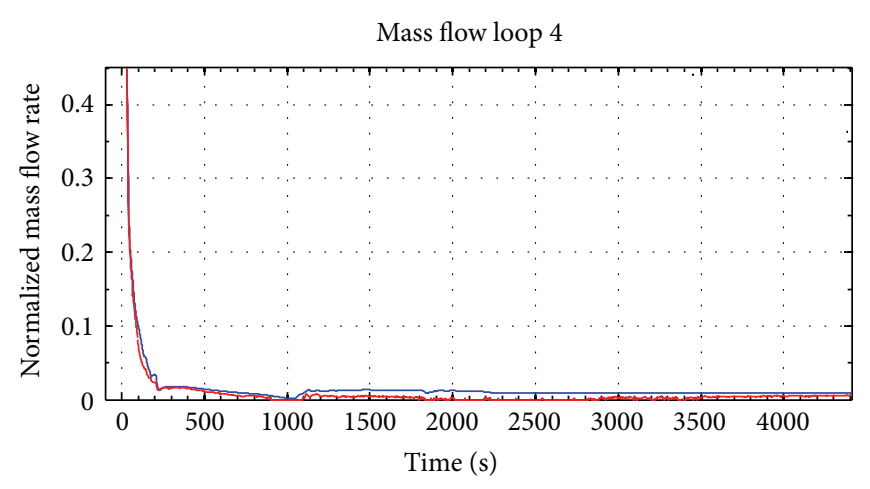

(i)

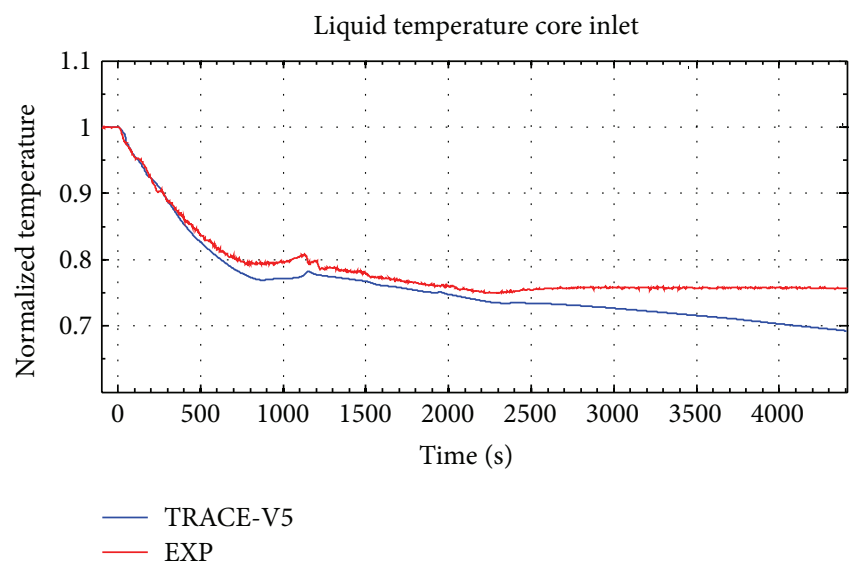

$(\mathrm{k})$

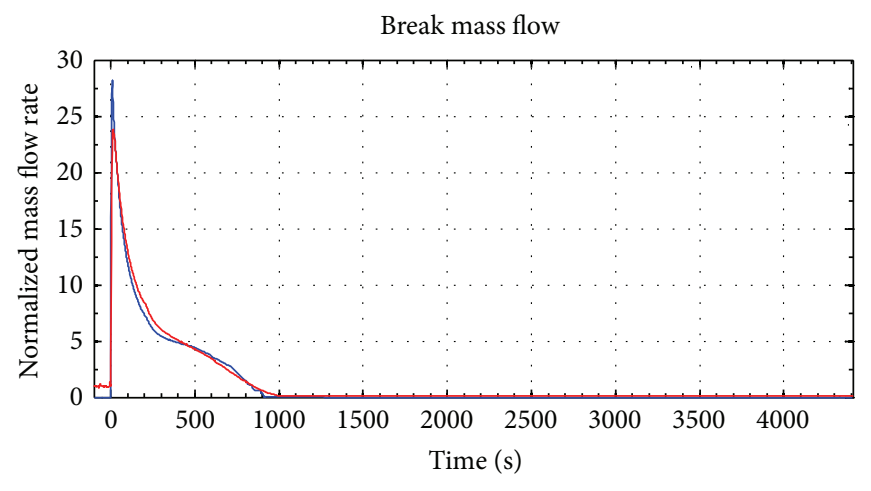

(j)

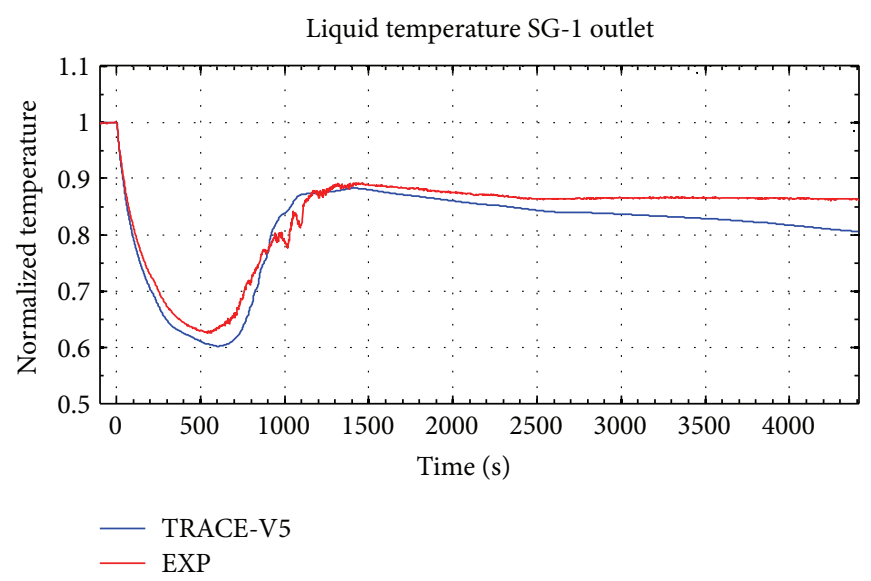

(1)

FIGURE 3: Parameter trends (normalized to SoT (start of transient) values), comparison among experimental data, and calculated results (part 1 of 2). Parameter trends (normalized to SoT), comparison among experimental data, and calculated results (part 2 of 2).

each contribution is dependent on the experimental accuracy, the relevance of the addressed parameter, and a component of normalization with reference to the average amplitude evaluated for the primary side pressure.

Trying to give an overall picture of the accuracy of a given calculation, average indexes of performance are obtained by defining average performance indices: the total weighted amplitude $\mathrm{AA}_{\text {tot }}$ and total weighted frequency $\mathrm{WF}_{\text {tot }}$ (see (1) and (2)):

$$
\begin{aligned}
(\mathrm{AA})_{\mathrm{tot}} & =\sum_{i=1}^{N_{\mathrm{var}}} A A \cdot\left(w_{f}\right)_{i}, \\
(\mathrm{WF})_{\mathrm{tot}} & =\sum_{i=1}^{N_{\mathrm{var}}}(\mathrm{WF})_{i}\left(w_{f}\right)_{i},
\end{aligned}
$$

With

$$
\sum_{i=1}^{N_{\text {var }}}\left(w_{f}\right)_{i}=1,
$$

where $N_{\text {var }}$ is the number of analyzed parameters and $\left(w_{f}\right)_{i}$ are weighting factors that take into account the different importance of each parameter from the viewpoint of safety analyses.
Following the quantitative evaluation of accuracy, the QA (quantitative assessment) can be managed by means of the application of the FFT method. Obviously, the most suitable factor for the definition of an acceptability criterion is the average amplitude (AA). With reference to the accuracy of a given calculation, we can define the following acceptability criterion:

$$
(\mathrm{AA})_{\text {tot }}<K,
$$

where $K$ is an acceptability factor that is valid for the whole transient. The origin for quantifying the acceptability limits is constituted by the state-of-the-art capabilities of current system generation of the best estimate thermal-hydraulics system codes. A large number of complex transients, including small break LOCA, large break LOCA, and long-lasting transients, have been analyzed by the methodology based on the FFT using all the codes available to the international community (RELAP5, TRACE, ATHLET, CATHARE, etc.); several hundreds of time quantities have been dealt with in such a way. In a number of cases detailed, and independent code accuracy evaluations were available (this is the case of international standard problems (ISPs) 26 and 27) leading to the conclusion that an excellent calculation could be characterized by $K=0.3$. In turn, a poor calculation 
(i.e., a calculation predicting all the relevant experiment phenomena with poor accuracy) could be characterized by $K=0.5$ [9]. It can be noted that

(1) $\mathrm{AA}_{\text {tot }} \leq 0.3$ characterize very good predictions;

(2) $0.3 \mathrm{AA}_{\text {tot }}-0.5$ characterize good code predictions;

(3) $0.5 \_\mathrm{AA}_{\text {tot }}-0.7$ characterize poor code predictions;

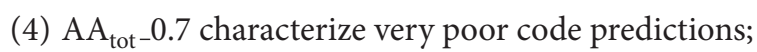

The same criterion can be used to evaluate the code capability in the single variable prediction; clearly, in this case, the AA factor is the one evaluated for the addressed variable. In particular, acceptability factor $K=0.1$ has been fixed for the primary pressure because of its importance [9].

\section{Conclusions}

The OECD/NEA CSNI PKL-2 (2008-2012) is aimed at studying selected accident scenario at system level and understanding the thermal-hydraulic phenomena and processes occurring in pressurized water reactor design as well as validating and improving complex thermal-hydraulic system codes used in safety analysis. This paper illustrates the analysis, performed by TRACE code, of the test G3.1, a fast cooldown transient caused by the rupture of the main steam line. The objective of the work is the qualification of the TRACE code against heat transfer from primary to secondary side in the intact and affected steam generators (SGs) during the rapid depressurization and the boiloff in the affected SG. The following outcomes can be inferred from the analysis:

(i) Considering phase I of the transient, with the pressure decreasing to high pressure injection start, the code is able to predict the trend of the main parameters with satisfactory accuracy. In particular, the break flow, the affected SG depressurization, the heat exchange primary to secondary, the RCS coolant temperatures at $\mathrm{U}$-tubes outlet, and also the primary pressure are in agreement with the experimental evidences.

(ii) The imperfect knowledge of the operation of the PRZ valve and limitations due to simplified assumptions in modelling the component constitute the main reasons of the difficulties in simulating phase II.

The application of the FFTBM shows that the total average accuracy rises above 0.2 considering the overall transient.

\section{References}

[1] A. Annunziato, H. Glaeser, J. Lillington, P. Marsili, C. Renault, and A. Sjöberg, "CSNI integral test facility validation matrix for the assessment of thermal-hydraulic codes for LWR," NEA/CSNI/R 96, 1996.

[2] IAEA, "Accident analysis for nuclear power plants," Safety Reports Series 23, IAEA, Vienna, Austria, 2002.

[3] H. Kremin, H. Limprecht, R. Guneysu, and K. Umminger, "Description of the PKL III test facility," FANP NT31/01/e30, Technical Centre of Framatome ANP, Erlangen, Germany, 2001.
[4] A. del Nevo, M. Adorni, F. D’Auria, and G. M. Galassi, "Capability of CATHARE2 V2. 5 code in simulating boron dilution following a SB-LOCA. comparison with PKL III results," DIMNP NT 634 (08) Rev1, University of Pisa, 2009.

[5] M. Bonuccelli, F. D’Auria, N. Debrecin, and G. M. Galassi, "A Methodology for the qualification of thermalhydraulic code nodalizations," in Proceedings of of Nuclear Reactor Thermalhydraulics Conference (NURETH' 6), Grenoble, France, October 1993.

[6] F. D’Auria, A. Bousbia-Salah, A. Petruzzi, and A. del Nevo, "State of the art in using best estimate calculation tools in nuclear technology," Nuclear Engineering and Technology, vol. 38, no. 1, pp. 11-32, 2006.

[7] United States Nuclear Regulatory Commission, TRACE V5.0 Theory Manual Field Equations, Solution Methods, and Physical Models, 2007.

[8] R. Bovalini, F. D’Auria, and M. Leonardi, "Qualification of the fast fourier transform based methodology for the quantification of thermalhydraulic code accuracy," DCMN Report, NT 194 (92), University of Pisa, Pisa, Italy, 1992.

[9] A. Prošek, F. D’Auria, and B. Mavko, "Review of quantitative accuracy assessments with fast Fourier transform based method (FFTBM)," Nuclear Engineering and Design, vol. 217, no. 1-2, pp. 179-206, 2002. 


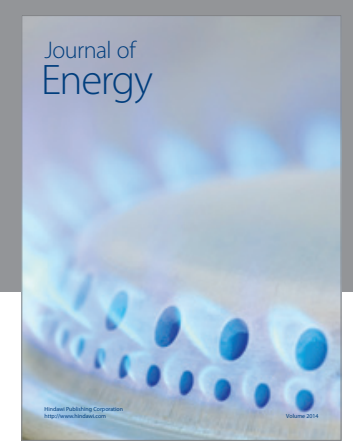

Journal of

Industrial Engineering
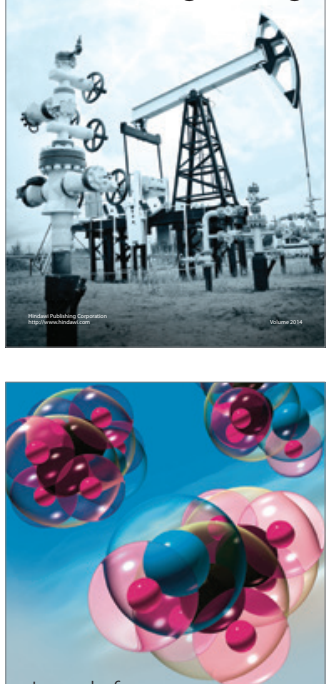

Fuels
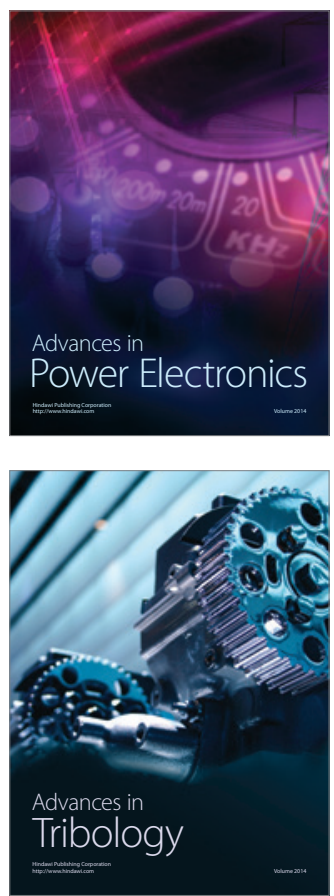

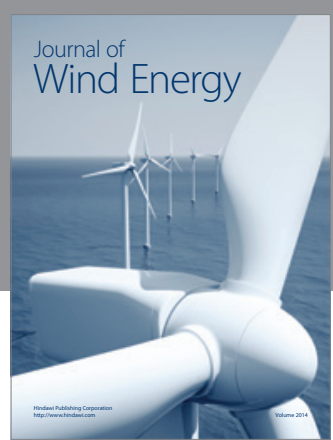

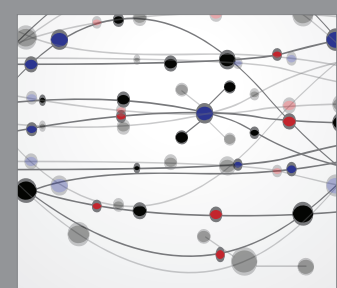

The Scientific World Journal

Submit your manuscripts at http://www.hindawi.com

Journal of

Structures
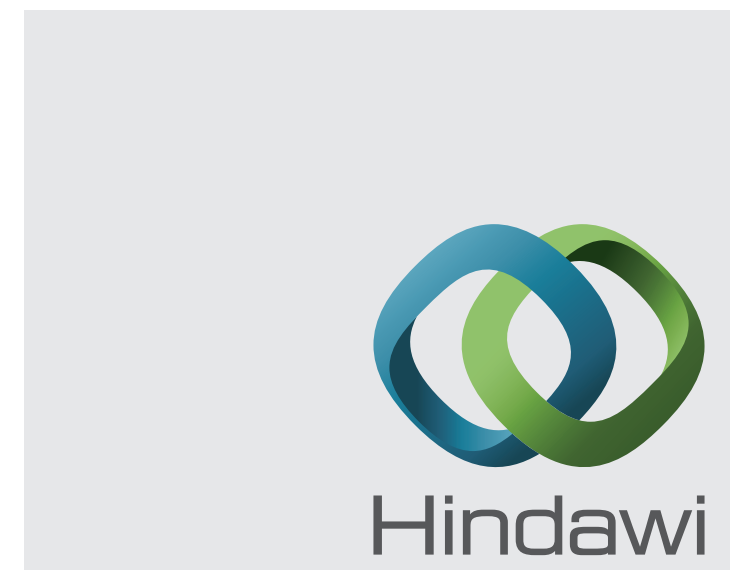

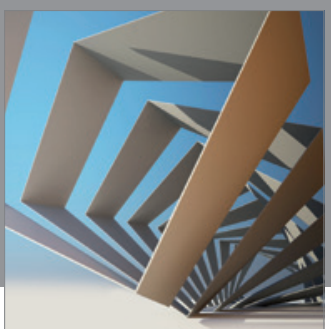

Rotating

Machinery
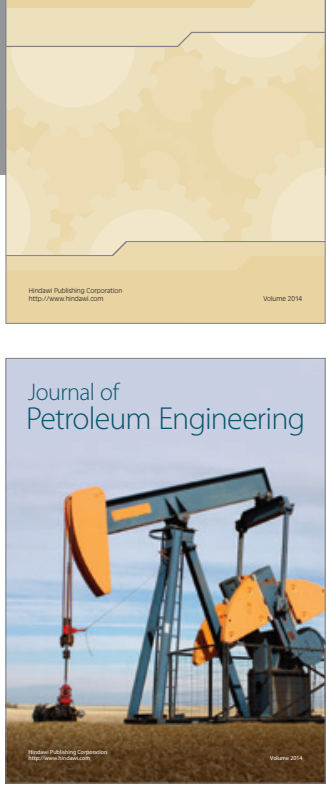

Journal of

Solar Energy
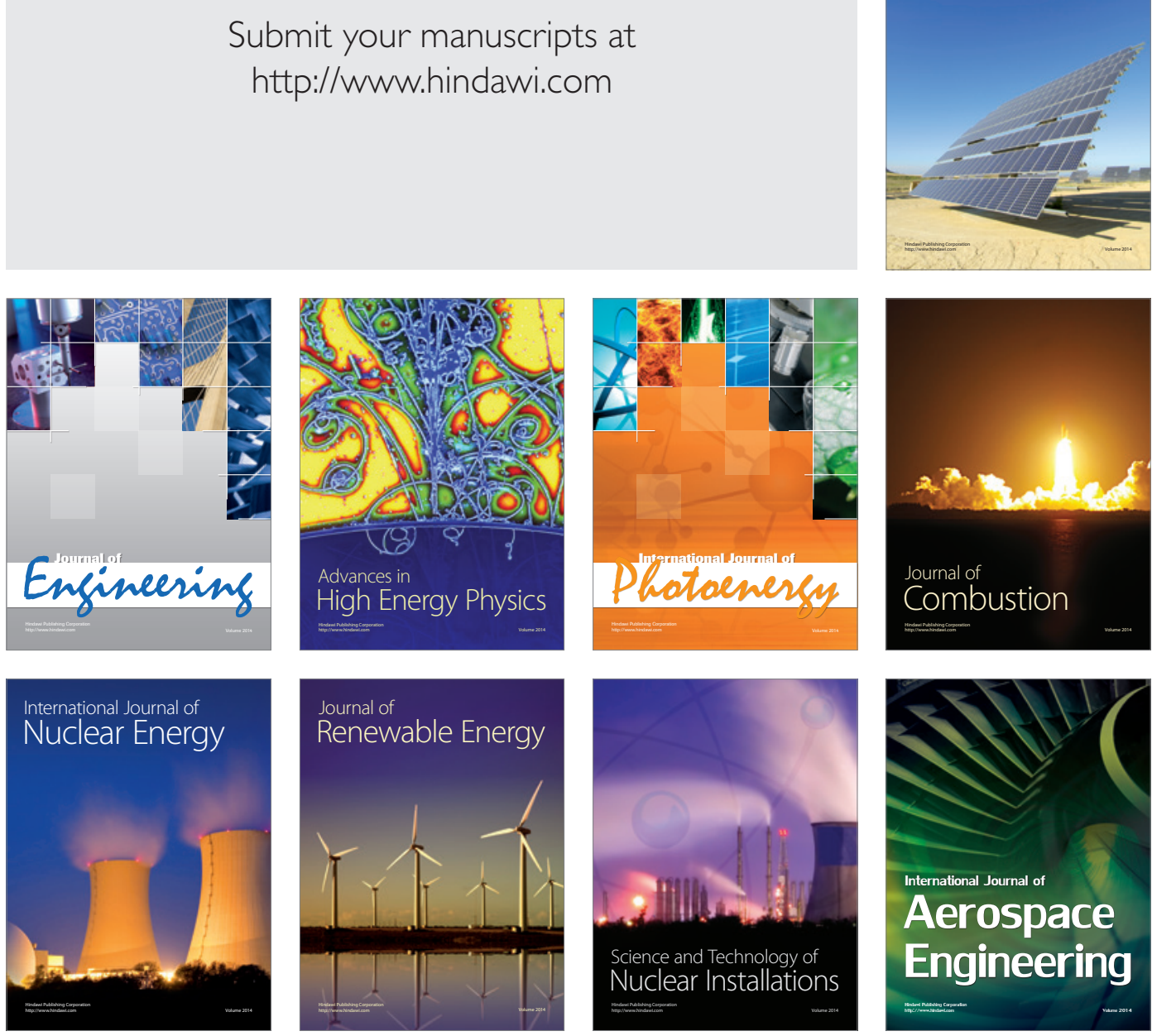